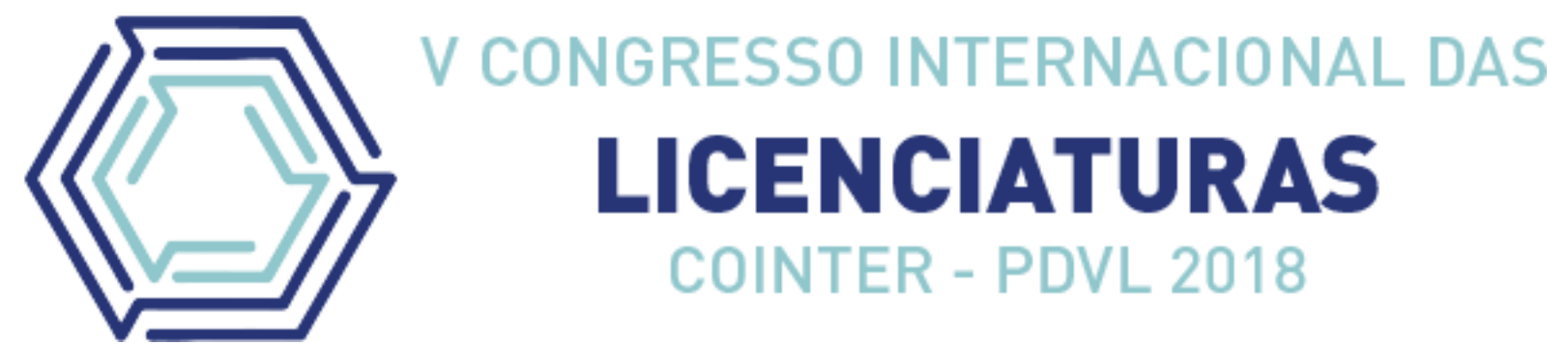

\title{
USO DE FRUTOS DO CERRADO PIAUIENSE COMO RECURSO DIDÁTICO NO ENSINO DE BIOLOGIA
}

\section{USE OF FRUITS OF THE PIAUIENSE CERRADO FOR THE TEACHING OF BIOLOGY}

\author{
Apresentação: Pôster
}

Dálet Helen Vasconcelos Veras Lima ${ }^{1}$; Maria Helena Lima dos Santos ${ }^{2}$; Larisse dos Santos Fernandes ${ }^{3}$; Carlos Eduardo Castro Ribeiro ${ }^{4}$; Divamélia de Oliveira Bezerra Gomes ${ }^{5}$

\section{DOI: https://doi.org/10.31692/2358-9728.VCOINTERPDVL.2018.00246}

\section{Introdução}

A botânica compreende uma das áreas das ciências biológicas que requer conhecimento aplicado de forma prática em sala de aula. Seu objetivo de estudo: a flora dos diferentes biomas e ecossistemas, entre eles, aqui para o nordeste do Brasil, o cerrado e a caatinga. Para uma melhor compreensão do bioma e suas relações, faz-se reunir uma interação com seus fatores físicos, químicos e biológicos, e a botânica é com certeza, a ciência que mais se aproxima desta inter relação.

Desta forma, deve ser ministrada de maneira prática, o que no entanto não acontece nas rotinas escolares seja em nível médio como na graduação, conforme afirma Almeida e Costa e Silva (2008). Os autores asseguram ainda que, grande parte dos jovens de zona urbana desconhecem os elementos que caracterizam o bioma cerrado.

Para esta abordagem o ensino de botânica em si é um ramo da Biologia que trabalha especialmente a morfologia, classificação, identificação, reprodução, fisiologia, distribuição e as relações de plantas, fungos e algas sendo entre as mesmas ou outros seres vivos . Porém, esta ciência vem sendo tratado em segundo plano, tanto no currículo, quanto nas metodologias a serem eficazes para a transmissão do conhecimento pelo professor (STANKY, C, et.al, 2016).

Assim, devido a este obstáculo, o ensino de botânica ainda é visto como um conteúdo desestimulante e, infelizmente, as escolas brasileiras atuais não apresentam estrutura eficaz que 'Licenciatura em Ciências Biológicas, Instituto Federal do Piauí, daletveras@gmail.com ${ }^{2}$ Licenciatura em Ciências Biológicas, Instituto Federal do Piauí, helennamaria410@gmail.com ${ }^{3}$ Licenciatura em Ciências Biológicas, Instituto Federal do Piauí, Ilamafernandes04@gmail.com ${ }^{4}$ Licenciatura em Ciências Biológicas, Instituto Federal do Piauí, c.c.kadu@gmail.com

${ }^{5}$ Professora Doutora, Instituto Federal do Piauí, divamelia@ifpi.edu.br 
permitam aos professores trabalhem esta disciplina de maneira significativa dentro da sala de aula (KINOSHITA et, al., 2006).

Portanto, o presente trabalho teve como objetivo, o incentivo ao estudo de Botânica através da utilização de frutos do bioma Cerrado piauiense, como recurso didático para o aprendizado de Botânica e como alternativa metodológica para o ensino desta ciência.

\section{Fundamentação Teórica}

Mesmo reconhecendo a necessidade e relevância de se realizar uma aula expositiva ou atividades práticas em sala de aula, está rotina continua não acontecendo por parte do corpo docente (LIMA, 2004). Diante desta dificuldade, causa ao corpo docente um certo desinteresse, principalmente quando o assunto são os vegetais, pois além da falta de procedimentos tem-se a ausência de materiais didáticos que auxiliam no processo de aprendizagem (MELO et al., 2012; MINHOTO, 2003).

Muitas vezes essas aulas resumem-se apenas em aulas expositivas onde são usadas receitas prontas situadas nos livros didáticos, causando a problemática com que se mantenha a forma mecânica como os conteúdos dos livros didáticos são transmitidos (SANTOS E MACEDO 2012).

Sendo assim, aulas práticas são significativas para a aprendizagem por parte dos discentes nas aulas de Botânica, possibilitando aos mesmos a chance de associar os conteúdos abordados em sala com seu dia-a-dia, e dessa forma aproximando os assuntos abordados do seu cotidiano (TOWATA et al., 2010). Desse modo a visualização e o contato com amostras de diversos grupos de vegetais podem proporcionar aos discentes a contextualização do assunto visto anteriormente apenas em teoria, melhorando assim a assimilação do conteúdo e sua visão da diversidade existente (SILVIA e GHILARDI-LOPES, 2014).

Zompero \& Laburú (2010), fizeram uma pesquisa no qual intercedem o propósito de que um método variado no ensino que utilize os diversos modos de representação para melhorar os resultados relativos ao aprendizado dos alunos e, que vem ganhando espaço nas discussões e nos hábitos educacionais, oferecendo resultados melhores em relação à apreensão e semelhanças do conteúdo.

\section{Metodologia}

Esta pesquisa foi realizada com natureza quali-quantitativa, e foi realizada em etapas a 
seguir descritivas para consecução dos objetivos e para tornar o curso de botânica mais atrativo e significativo. Os frutos foram coletados em uma área do cerrado no estado do Piauí, devidamente adicionados e sacos plásticos e identificados no laboratório de Botânica do IFPI, campus Teresina Central. Logo após serem nomeados com seus nomes científicos foi aplicado aos alunos de graduação de ciências biológicas no Instituto Federal do Piauí do Campus Teresina Central da cidade de Teresina Piauí, questionários contendo questões abertas e fechadas voltada às questões da botânica aplicada à ciência e biologia, ou seja, questões que abrangem apenas o conhecimento básico. Logo após os resultados foram tabulados.

\section{Resultados e Discussões}

Gráfico 1- AULAS PRÁTICAS COM/SEM FRUTOS DO CERRADOS OU DA CAATINGA

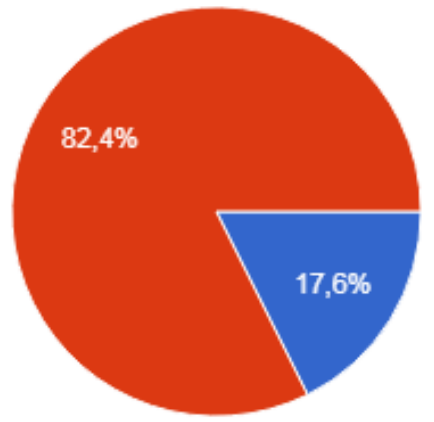

Fonte: elaborado pelo autor 


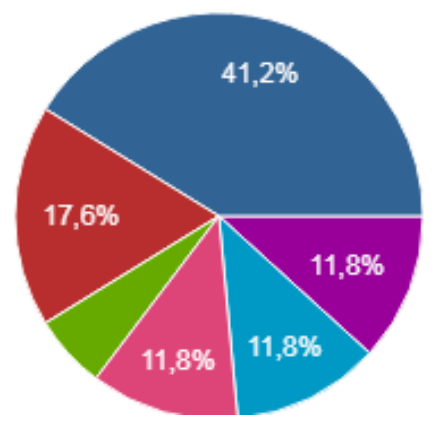

Fonte: elaborado pelo autor

As questões que foram aplicadas aos alunos de Biologia demonstrou que grande maioria não sabia definir um fruto de forma específica e compreensível, assim colocando respostas curtas ou não respondendo. Foi avaliado a importância da botânica no contexto da biologia, onde 41,2\% (gráfico 1) conceituou com nota 10 e 11,8\% a 5 a classificação. Outra pergunta que foi questionada foi sobre aulas práticas com frutos do cerrado ou caatinga encontrado na mata, $82,4 \%$ (gráfico 2) afirmaram não terem hábito esses materiais, porém sabem da existência de algum tipo de frutos deste bioma.

\section{Conclusões}

Dessa forma podemos entender que o uso do material didático é um método que contribui para o aprendizado dos alunos. Ao usar materiais da região ou até mesmo coletados em áreas próximas é possível executar uma aula inovadora, assim despertando o interesse para novas descobertas na sala de aula e expondo a riqueza da biodiversidade e despertando o interesse pela botânica.

\section{Referências}

Algas Bioindicadoras e o ensino de biologia: Um estudo de caso no parque lagoas do norte, PI. ALMEIDA, S. P. de; COSTA, T. da S. A.; SILVA, J. A. da; Frutas nativas do Cerrado. Caracterização físico-química e fonte potencial de nutrientes. In: SANO, S. M.; ALMEIDA, S. P. de; RIBEIRO, J. F. Cerrado: ecologia e flora. Brasília: Embrapa, v. 1, 2008. 
KINOSHITA, L.S., TORRES, R.B., TAMASHIRO, J.Y., FORNI-MARTINS, E.R. A Botânica no Ensino Básico: relatos de uma experiência transformadora. RiMa, São Carlos, p. 162. 2006.

LIMA, V. A. (2004). Atividades Experimentais no Ensino Médio: reflexão de um grupo de professores a partir do tema eletroquímica. Dissertação. São Paulo: USP.

Melo, E. A., Abreu, F. F., Andrade, A. B., e Araujo, M. I. O. (2012). A aprendizagem de Botânica no Ensino Fundamental: dificuldades e desafios. Scientia Plena, 8, 10, 1-8.

SANTOS, R. M., MACEDO, G. E. L. (2012). A prática pedagógica do Ensino de Botânica nas escolas do município de Jequié, Bahia, Brasil. X Jornadas Nacionales V Congreso Internacional de Enseñanza de la Biología: Entretejiendo la enseñanza de la Biología en una urdimbre emancipadora.

SILVA, J. N., e GHILARDI-LOPES, N. P. (2014). Botânica no Ensino Fundamental: diagnósticos de dificuldades no ensino e da percepção e representação da biodiversidade vegetal por estudantes. Revista Electrónica de Enseñanza de las Ciencias, 13, 2, 115-136.

STANSKI, Carin et al . Ensino de Botânica no Ensino Fundamental: estudando o pólen por meio de multimodos. Hoehnea, São Paulo, v. 43, n. 1, p. 19-26, Mar. 2016 . Disponível em: $<$ http://www.scielo.br/scielo.php?script=sci_arttext\&pid=S2236-

89062016000100019\&lng=en\&nrm=iso>. acessado em $10 \quad$ Out. 2018. http://dx.doi.org/10.1590/2236-8906-34/2015.

TOWATA, N., Ursi, S., e Santos, D. Y. A. C. (2010). Análise da percepção de licenciandos sobre o Ensino de Botânica na educação básica. Revista da SBEnBio, 3, 1, 1603-1612.

Zompero, F.A. \& Laburú, C.E. As relações entre aprendizagem significativa e representações multimodais. Revista Ensaio, 2010. 